\title{
Restoring the endangered oyster mussel (Epioblasma capsaeformis) to the upper Clinch River, Virginia: an evaluation of population restoration techniques
}

\author{
Caitlin S. Carey ${ }^{1,2,3}$, Jess W. Jones ${ }^{4}$, Robert S. Butler ${ }^{5}$, Eric M. Hallerman ${ }^{6}$
}

From 2005 to 2011, the federally endangered freshwater mussel Epioblasma capsaeformis (oyster mussel) was reintroduced at three sites in the upper Clinch River, Virginia, using four release techniques. These release techniques were (1) translocation of adults (site 1, $n=1418$ ), (2) release of laboratory-propagated sub-adults (site 1, $n=2851$ ), (3) release of 8-week-old laboratory-propagated juveniles (site $2, n=9501$ ), and (4) release of artificially infested host fishes (site $3, n=1116$ host fishes). These restoration efforts provided a unique research opportunity to compare the effectiveness of techniques used to reestablish populations of extirpated and declining species. We evaluated the relative success of these four population restoration approaches via monitoring at each release site (2011-2012) using systematic $0.25-\mathrm{m}^{2}$ quadrat sampling to estimate abundance and post-release survival. Abundances of translocated adult and laboratory-propagated sub-adult E. capsaeformis at site 1 ranged 577-645 and 1678-1700 individuals, respectively, signifying successful settlement and high post-release survival. Two untagged individuals $(29.1$ and $27.3 \mathrm{~mm})$ were observed, indicating that recruitment is occurring at site 1 . No $E$. capsaeformis were found at sites where 8-week-old laboratory-propagated juveniles (site 2) and artificially infested host fishes (site 3) were released. Our results indicate that translocations of adults and releases of laboratory-propagated sub-adults were the most effective population restoration techniques for E. capsaeformis. We recommend that restoration efforts focus on the release of larger $(>20 \mathrm{~mm})$ individuals to accelerate augmenting and reintroducing populations and increase the probability for recovery of imperiled mussels.

Key words: artificial infestation of host fishes, augmentation, endangered species, freshwater mussels, laboratory propagated, reintroduction, translocation

\section{Implications for Practice \\ - Freshwater mussel reintroduction efforts should focus on translocating adults and releasing larger $(>20 \mathrm{~mm})$ laboratory-propagated individuals to maximize success of population restoration projects. \\ - Releasing larger individuals presents the opportunity to tag and follow cohorts through time and increases the knowledge of species-specific demographics. \\ - Biotic and abiotic factors may limit the survival of reintro- duced individuals, and should be identified and controlled for before releasing individuals. \\ - Post-release monitoring and documentation of successes and failures of restorations is vital to improving the effi- cacy of future projects.}

\section{Introduction}

Freshwater mussels are the most imperiled taxa in the United States. In recent years, reintroductions of extirpated mussel species into restored habitats where they historically occurred, and augmentations of extant but generally declining populations, have become crucial for recovering species and mitigating losses from numerous anthropogenic impacts and the effects of population fragmentation (Neves et al. 1997; Haag 2012; Haag \& Williams 2014). In addition to verifying suitable habitats, restoring populations to previously occupied habitats requires adaptive management_-including assessments to identify the most efficient techniques for restoring and monitoring populations (Sarrazin \& Barbault 1996). We evaluated four

\footnotetext{
Author contributions: JJ, BB conceived, designed, and obtained funding for reintroductions; $\mathrm{CC}, \mathrm{JJ}, \mathrm{BB}$ implemented reintroductions and conducted post-release monitoring surveys; $\mathrm{CC}$ designed post-release monitoring surveys and analyzed the data; EH, JJ, BB contributed materials, transportation, and laboratory space and equipment; $\mathrm{CC}, \mathrm{JJ}, \mathrm{EH}, \mathrm{BB}$ wrote the manuscript.

${ }^{1}$ Department of Fish and Wildlife Conservation, Virginia Polytechnic Institute and State University, Blacksburg, VA 24061, U.S.A.

${ }^{2}$ Address correspondence to C. S. Carey, email cscarey@vt.edu

${ }^{3}$ Present address: Conservation Management Institute, Virginia Polytechnic Institute and State University, 1900 Kraft Drive, Suite 250, Blacksburg, VA 24061, U.S.A. ${ }^{4}$ U.S. Fish and Wildlife Service, Department of Fish and Wildlife Conservation, Virginia Polytechnic Institute and State University, Cheatham Hall, Room 106a, 310 West Campus Drive, Blacksburg, VA 24061, U.S.A.

${ }^{5}$ U.S. Fish and Wildlife Service, Asheville Field Office, 160 Zillicoa Street, Asheville, NC 28801, U.S.A.

${ }^{6}$ Department of Fish and Wildlife Conservation, Virginia Polytechnic Institute and State University, Integrated Life Sciences Building, Room 1021, 1981 Kraft Drive, Blacksburg, VA 24061, U.S.A.
}

(C) 2015 Society for Ecological Restoration

doi: $10.1111 /$ rec. 12195

Supporting information at:

http://onlinelibrary.wiley.com/doi/10.1111/rec.12195/suppinfo 
restoration techniques to determine the most successful approach for reestablishing viable populations of the endangered Epioblasma capsaeformis (oyster mussel), a mussel endemic to the Tennessee and Cumberland River drainages of the southeastern United States.

The native population of E. capsaeformis in the upper Clinch River, Virginia, has severely declined over the past 50 years, and is essentially undetectable using typical sampling methodologies, if not already extirpated. This decline was due to habitat and water quality degradation from various anthropogenic impacts, including poorly treated sewage, chemical spills, coal mining, and other human-related activities. Over the past 20 years, improvements to wastewater treatment facilities and subsequent improvements in habitat and water quality have allowed the mussel and fish fauna to recover within portions of the upper Clinch River (Eckert \& Pinder 2010; Jones et al. 2014; Price et al. 2014). In 2002, the Virginia Department of Game and Inland Fisheries (VDGIF) designated a 19-km reach of the river ( $\mathrm{km} \mathrm{430-449)}$ as suitable for conducting restoration of E. capsaeformis and other extirpated or declining species (Eckert \& Pinder 2010). In efforts to reestablish the population of E. capsaeformis in the upper Clinch River and meet delisting criteria, reintroductions were conducted by VDGIF and U.S. Fish and Wildlife Service (USFWS) over a period of 7 years (2005-2011) using translocation and captive propagation methods recommended by recovery plans for listed mussels (USFWS 2004).

Foremost in post-reintroduction evaluations is the need to clearly identify what constitutes a successful reintroduction (Sarrazin \& Barbault 1996), that is, provide measurable goals for evaluating success and reference points for comparisons to other projects. One such ecological criterion of reintroduction success is the establishment of a long-term viable population (Griffith et al. 1989). Other studies have described a short-term measure of reintroduction success as the documentation of natural recruitment (Cope \& Waller 1995; Sarrazin \& Barbault 1996), while others have used three criteria: (1) settlement of released individuals, (2) post-release survival of individuals, and (3) natural recruitment (Teixeira et al. 2007). Using these three suggested criteria, we sought to evaluate four techniques used to reintroduce E. capsaeformis into the upper Clinch River by conducting intensive post-release monitoring.

Although hundreds of thousands of mussels have been translocated and released over the past 15-20 years, detailed reports of specific techniques and monitoring results are limited. Post-release monitoring and reporting results (both positive and negative) are essential to assessing reintroduction success, improving restoration plan efficiency, providing biologists with data required for effective management, and evaluating whether down- or delisting criteria have been met (Sarrazin \& Barbault 1996; Sarrazin \& Legendre 2000; USFWS 2004; Jones \& Neves 2011). The objectives of our study were to: (1) provide biologists with accessible reintroduction monitoring data, (2) determine which release strategy was most effective at restoring populations of E. capsaeformis in the upper Clinch River, and (3) provide recommendations applicable to mussel population recovery efforts.

\section{Methods}

\section{Study Sites}

From 2005 to 2011, Epioblasma capsaeformis were reintroduced at three study sites within a $6.1-\mathrm{km}$ reach of the upper Clinch River in Russell County, Virginia, using the following techniques: translocation of adults, release of laboratory-propagated sub-adults (LPSA), release of 8-week-old laboratory-propagated juveniles (i.e. newly metamorphosed juveniles; 8 weeks after excystment from their host fish), and release of artificially infested host fishes. Each study site contains a diverse native-mussel community, darter fish hosts (family Percidae) utilized by E. capsaeformis and other mussel species, suitable water quality and hydrological conditions, and stable gravel substrates (Eckert \& Pinder 2010; Jones et al. 2014; Price et al. 2014; Table S1, Supporting Information). Three of the reintroduction techniques were implemented in two distinct flowing channels at Cleveland Islands (Clinch River kilometer [CRKM] 435.8, sites 1 and 2). At Cleveland Islands, translocated adults and LPSAs were released together in the left-descending channel, site $1\left(36^{\circ} 56^{\prime} 15.10^{\prime \prime} \mathrm{N}\right.$, $82^{\circ} 9^{\prime} 45.05^{\prime \prime} \mathrm{W}$ ), and 8-week-old laboratory-propagated juveniles were released in the right-descending channel, site 2 $\left(36^{\circ} 56^{\prime} 16.96^{\prime \prime} \mathrm{N}, 82^{\circ} 9^{\prime} 51.85^{\prime \prime} \mathrm{W}\right)$. Each individual released at site 1 was uniquely tagged (shellfish tag; Hallprint, Inc., Holden Hills, Australia), measured for length ( $\mathrm{mm}$ ), and sexed (sexual dimorphism of female and male shells) for identification purposes. The fourth technique was implemented further upstream near the town of Artrip (CRKM 441.9), site $3\left(36^{\circ} 57^{\prime} 44.72^{\prime \prime} \mathrm{N}\right.$, $82^{\circ} 7^{\prime} 12.64^{\prime \prime} \mathrm{W}$ ), where eight separate (two per year) artificial infestations of native host fishes with $E$. capsaeformis glochidia were conducted (Fig. 1). Translocated adults and those used for captive propagation were collected from several healthy source populations in the lower Clinch River, Tennessee (Jones et al. 2014). Reintroduction efforts are summarized in Table 1.

To determine the upstream and downstream boundaries of each reintroduction site for post-release monitoring, we conducted preliminary qualitative snorkel surveys. Observation of live E. capsaeformis or shells, the presence of other mussels, and habitat characteristics were taken into consideration for delineating the boundaries of the sampling area.

\section{Post-release Survival Predictions}

Survival rates of $E$. capsaeformis from one age class to the next were obtained from data collected by Jones and Neves (2011) in the lower Clinch River, Tennessee, and presented in Jones et al. (2012). Using these age-class survival transition probabilities in combination with age-at-release data, we predicted the proportion of originally released individuals that could have survived from each reintroduction technique to 2011 and 2012. To predict post-release survival rates of individuals at site 3, we determined the number of glochidia that would be expected to have successfully transformed and excysted (i.e. as a newly metamorphosed juvenile) from each artificially infested host fish released. Using a combination of empirical data from published works and host fish and mussel fecundity studies 


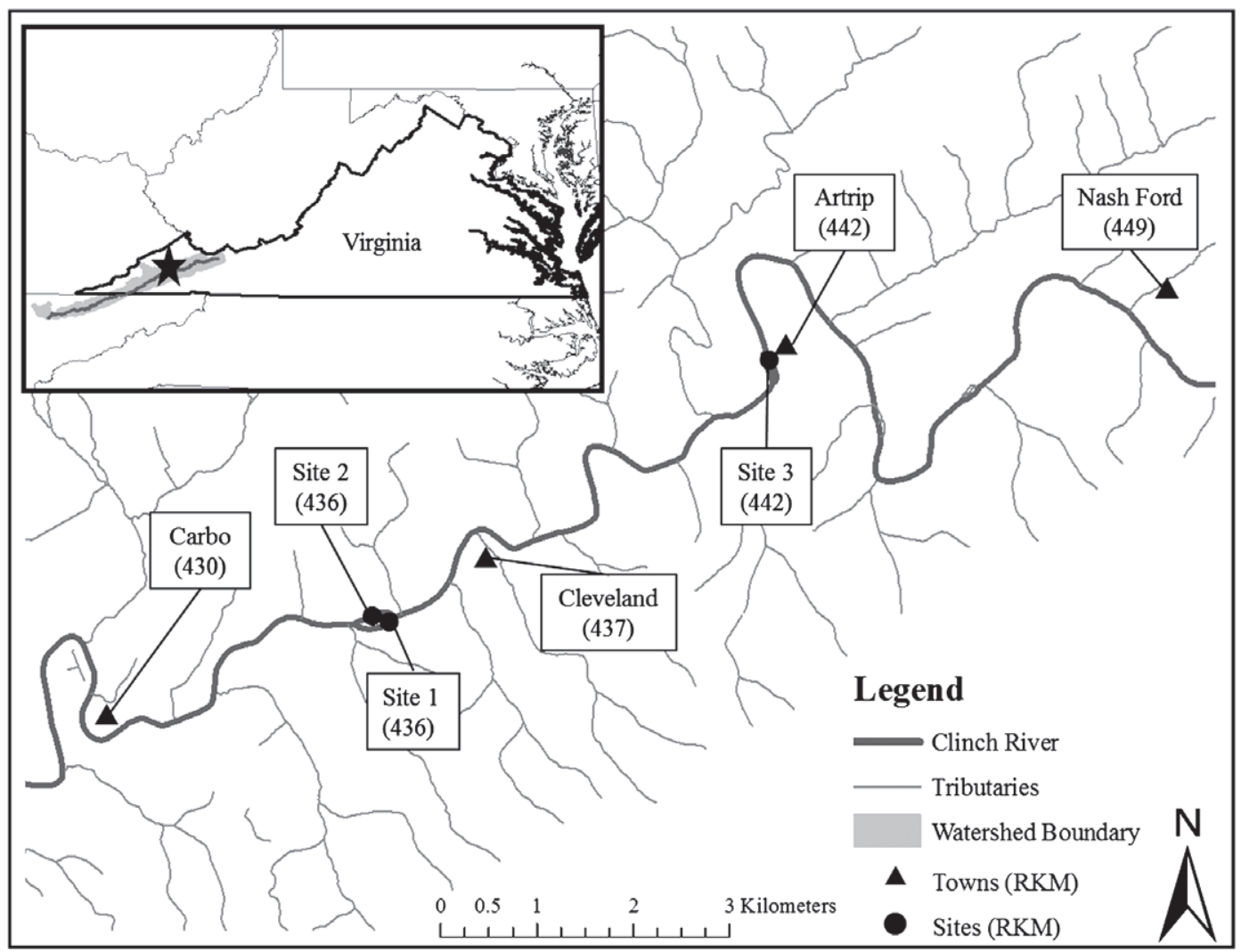

Figure 1. Locations of Epioblasma capsaeformis reintroduction sites (river kilometer) in the upper Clinch River, from Nash Ford to Carbo, Russell County, Virginia, U.S.A.

(Freshwater Mollusk Conservation Center [FMCC], Virginia Polytechnic Institute and State University [Virginia Tech] unpublished data), we estimated that an average of 22 viable juveniles excysted per fish.

\section{Sampling Design}

To estimate abundance and post-release survival, sampling was conducted at site 1 in 2011 and 2012 and at sites 2 and 3 in 2012 using a systematic sampling (probability-based) design with $0.25-\mathrm{m}^{2}$ quadrat units. Spatial distributions of E. capsaeformis within each site were assumed to be random. The number of quadrat units required to estimate abundance with a desired precision level of $15 \%(\mathrm{CV}=\mathrm{SE} /$ mean $)$ at each site was dependent on expected densities (i.e. post-release survival predictions divided by the effective sampling area); that is, sample size requirements increased as expected density decreased. Each quadrat was carefully hand-excavated to a depth of approximately $15 \mathrm{~cm}$. The area covered by the sampling units was similar among sites. All E. capsaeformis sampled were sexed and measured for length. Any untagged E. capsaeformis were tagged, examined for indication of a previous tag (the presence of glue on the shell), estimated for age, and photographed if suspected to be a new recruit. All mussels and excavated substrate were returned to their original collection location. It was assumed that all individuals more than 1 year old had a $100 \%$ probability of detection within a quadrat. Due to their small size $(<10-15 \mathrm{~mm})$ and in the absence of sieving of substrates from quadrats in our study, individuals less than 1 year were more difficult to detect during sampling and were not included in population size estimations. Therefore, abundance was defined as the total number of $\geq 1$-year-old E. capsaeformis in the study area at a particular point in time. Post-release survival was calculated by dividing abundance (of reintroduced individuals) estimates by the total number of released individuals per reintroduction technique and was defined as the proportion of initially released individuals surviving. Detailed methods for this study design are available in the study by Carey (2013).

\section{Data Analysis}

Epioblasma capsaeformis abundance, post-release survival, and associated $95 \%$ confidence intervals were estimated separately for surviving reintroduced individuals and natural recruits at each site following systematic sampling formulae given by Smith et al. (2001). We evaluated settlement and survival of released E. capsaeformis from each reintroduction approach by comparing abundance and post-release survival between observed and predicted-point estimates. To evaluate natural recruitment and compare release strategies, quadrat sampling data were compared between sites and years using generalized linear models, with systematic random starts treated as random 
Table 1. Numbers, ages, and sizes of Epioblasma capsaeformis released per year (2005-2011), and predicted estimates of released individuals alive in 2011 and 2012, at three sites in the upper Clinch River, Virginia, using four restoration techniques.

\begin{tabular}{|c|c|c|c|c|c|c|c|}
\hline Site & Restoration Technique & Year & No. of Released & Mean Age & $\begin{array}{c}\text { Mean } \\
\text { Size }(\mathrm{mm})\end{array}$ & \multicolumn{2}{|c|}{$\begin{array}{l}\text { Predicted Number of } \\
\text { Surviving Individuals }\end{array}$} \\
\hline \multirow[t]{4}{*}{1} & \multirow[t]{4}{*}{ Translocated adults } & 2006 & 201 & $4-5$ years & 37.3 & 58 & 34 \\
\hline & & 2007 & 197 & $3-4$ years & 33.8 & 107 & 81 \\
\hline & & 2008 & 218 & 3-4 years & 34.2 & 148 & 120 \\
\hline & & Total & 1418 & & & 999 & 843 \\
\hline \multirow[t]{3}{*}{1} & \multirow{3}{*}{ Laboratory-propagated sub-adults } & 2010 & 2501 & $1-2$ years & 20.7 & 2376 & 2257 \\
\hline & & 2011 & 350 & $1-2$ years & 19.4 & 350 & 333 \\
\hline & & Total & 2851 & & & 2726 & 2590 \\
\hline \multirow[t]{2}{*}{2} & \multirow[t]{2}{*}{ 8-week-old laboratory-propagated juveniles } & 2005 & 3045 & 8 weeks & $0.5-1.0$ & 632 & 506 \\
\hline & & 2006 & 1595 & 8 weeks & $0.5-1.0$ & 390 & 331 \\
\hline \multirow{4}{*}{3} & \multirow{4}{*}{ Artificial infestations of host fish ${ }^{b}$} & 2008 & 6424 & 0 days & $<0.5$ & 1739 & 1652 \\
\hline & & 2009 & 7722 & 0 days & $<0.5$ & 2201 & 2091 \\
\hline & & 2010 & 5720 & 0 days & $<0.5$ & 1716 & 1630 \\
\hline & & Total & 24,552 & & & 6951 & 6518 \\
\hline
\end{tabular}

${ }^{a}$ Numbers of individuals predicted to survive are based on age-class survival transitional probabilities presented in Jones et al. (2012).

${ }^{b}$ Estimated number of released juveniles. Estimated mean number of viable newly metamorphosed juveniles per host fish $=22$. Newly metamorphosed juveniles equivalent to 0 days old.

effects. All analyses were conducted in SAS (Proc GLM, SAS Institute, Inc., Cary, North Carolina, U.S.A., version 9.2) and were considered statistically significant at $\alpha=0.05$.

\section{Results}

\section{Site 1}

Based on our age-class survival projections, the proportion of initially released translocated adult and LPSA Epioblasma capsaeformis predicted to survive were 70 and $96 \%$ in 2011, and 59 and $91 \%$ in 2012, respectively (Table 1; Fig. 2). Mean observed estimates of translocated adult and LPSA abundance and post-release survival were generally lower than the predicted-point estimates (Fig. 2). The numbers of translocated adult and LPSA encountered were similar between sampling years (Table 2). Collections of translocated adult E. capsaeformis within quadrats were composed of individuals from each of the 2007-2010 annual releases. Individuals from the 2006 translocation were only observed incidentally during preliminary qualitative surveys. All LPSA encountered in 2011 and 2012 were from the 2010 release.

Recruitment was documented during each sampling year at site 1. Lengths and estimated ages of the two individual recruits were $29.1 \mathrm{~mm}$ and 2-3years old in 2011, and $27.3 \mathrm{~mm}$ and 3-4 years old in 2012, respectively. Recruit abundance estimates between 2011 (mean $=52, \mathrm{SE}=26)$ and 2012 (mean $=59, \mathrm{SE}=29)$ were not significant $($ effect $=6$ individuals; $p>0.99)$.

\section{Sites 2 and 3}

The proportion of initially released E. capsaeformis predicted to survive at sites 2 and 3 were 24 and $28 \%$ in 2011, and 21 and $27 \%$ in 2012, respectively (Table 1). Although sampling effort was similar to that for site 1, no live or dead E. capsaeformis were detected at sites 2 and 3 where 8-week-old laboratory-propagated juveniles and infested host fish had been released (Table 2).

\section{Discussion}

Among the four reintroduction techniques implemented in this restoration project, our results showed that the translocation of adults and release of LPSAs were effective techniques for reestablishing populations of Epioblasma capsaeformis. Settlement, survival, and recruitment of E. capsaeformis were observed only at site 1 where translocated adults and LPSAs were released. Because no individuals were encountered at sites 2 and 3, we concluded that if E. capsaeformis were present at these sites, they occurred at very low densities and were essentially undetectable (i.e. likely much $<0.01 / \mathrm{m}^{2}$ ).

\section{Translocation of Adults and Release of Laboratory-propagated Sub-adults}

We considered reintroductions at site 1 a short-term success because both high post-release survival and natural recruitment were documented. Although survival estimates were generally lower than those predicted, this lower survival rate likely 

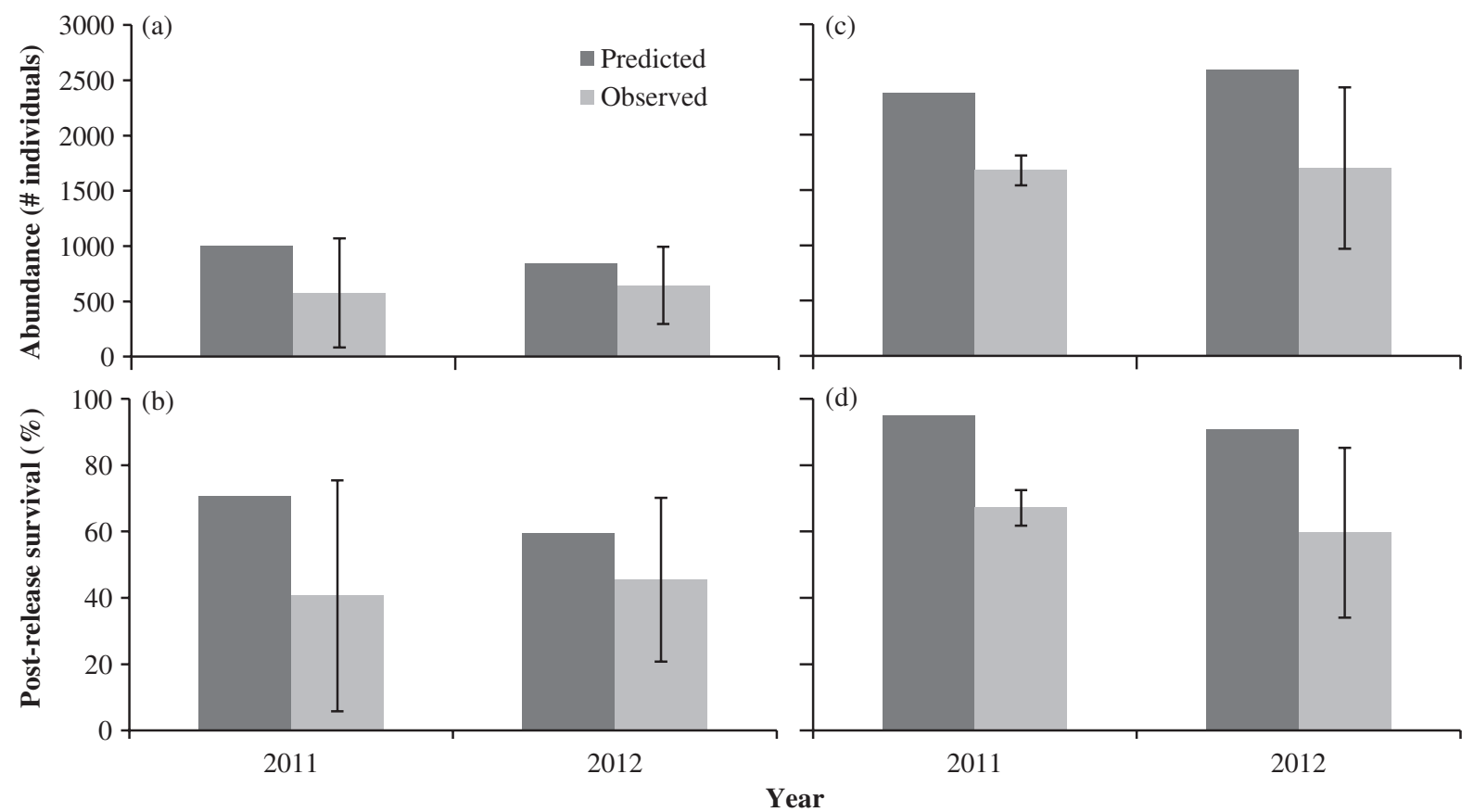

Figure 2. Comparing predicted-point to observed abundance and post-release survival estimates for translocated adult (a-b) and laboratory-propagated sub-adult (c-d) Epioblasma capsaeformis at Site 1 in the upper Clinch River, Virginia, in 2011 and 2012: predicted-point estimates from age-class survival transitional probabilities presented in Jones et al. (2012) and observed mean ( $\pm 95 \% \mathrm{CI})$ estimates from systematic quadrat sampling.

Table 2. Sample size ( $n$ ) of $0.25-\mathrm{m}^{2}$ quadrats, area covered (i.e. proportion of study site sampled), and number of Epioblasma capsaeformis encountered during systematic quadrat sampling conducted in 2011 and 2012, sorted by restoration technique, in the left-descending channel (site 1) and right-descending channel (site 2) of Cleveland Islands, and at Artrip (site 3) in the upper Clinch River, Virginia.

\begin{tabular}{|c|c|c|c|c|c|}
\hline Site & Year & Restoration Technique & $\mathrm{n}$ & Area Covered (\%) & No. of Encountered \\
\hline & & Laboratory-propagated sub-adults & & & 32 \\
\hline & & Total & & & 44 \\
\hline \multirow[t]{2}{*}{1} & 2012 & Translocated adults & 347 & 1.7 & 11 \\
\hline & & Laboratory-propagated sub-adults & & & 29 \\
\hline 2 & 2012 & 8-week-old laboratory-propagated juveniles & 210 & 1.8 & 0 \\
\hline 3 & 2012 & Juveniles from artificially infested host fishes & 194 & 1.8 & 0 \\
\hline
\end{tabular}

reflects higher initial mortality following release that is typical among reintroductions (Sarrazin \& Legendre 2000; Teixeira et al. 2007). Additional sources of variability in survival could be attributed to the loss of individuals from the site during high flow events following release or to differences in habitat characteristics between the upper and lower Clinch River. Taking these sources of variability into account, it is reasonable to conclude that translocated and released E. capsaeformis successfully settled into site 1 and may be surviving at annual rates similar to those reported in the lower Clinch River, Tennessee (Jones et al. 2012). Based on the time frame of our project, it was too early in the monitoring program to determine whether recruitment was occurring at self-sustaining levels (i.e. supporting establishment of a long-term viable population).
Other studies have reported generally low survival of translocated individuals (Sheehan et al. 1989). For instance, from 1976-1978, almost 3000 mussels of 16 species were reintroduced into historically occupied sites in the North Fork Holston River, Virginia (Ahlstedt 1979). During subsequent monitoring, large variability among results of translocation efforts were reported, with several reintroduced populations persisting longer than 5 years and others presumably washing out with flood events soon after translocation (Sheehan et al. 1989). Similar to our translocation success, Layzer and Scott (2006) documented relatively high survival of 18 species translocated to the lower French Broad River, Tennessee. Likewise, in 2008, the Kentucky Department of Fish and Wildlife Resources' Center for Mollusk Conservation (2009) observed 
$100 \%$ post-reintroduction survival of 300 individuals - 97 of which were $E$. capsaeformis -3 months after translocation to the Big South Fork Cumberland River, Kentucky. Increased success in translocations may reflect technical improvements, such as refined site selection based on a better understanding of species-specific habitat requirements, timing of release, and reduced stress from improved translocation methodologies.

Owing to advances in controlled propagation over the last decade (Jones et al. 2005; Barnhart 2006) allowing production of greater quantities of larger juveniles $(>15 \mathrm{~mm})$, it has become more feasible to conduct restorations using LPSAs. Although a few reports have documented short-term success from releasing LPSAs, longer-term successes are yet to be reported as the restoration technique is relatively new. For a closely related species Epioblasma brevidens (Cumberlandian combshell), monitoring of LPSAs a year after reintroduction into the Powell River, Tennessee, revealed high post-release survival (>98\%) and growth (Hua et al. 2011). Further insights into the long-term success of releasing LPSAs are anticipated in the near future as released individuals reach reproductive maturity.

\section{Releases of Newly Metamorphosed Juveniles and Infested Host Fishes}

Reintroduction efforts at sites 2 and 3 were not successful in our study. Given the predicted abundance and size of E. capsaeformis at sites 2 and 3 in 2012 (Carey 2013), they would have been easily detectable using our sampling methods. This nondetection of E. capsaeformis indicates that settlement and survival at sites 2 and 3 were poor, and significantly less than the rates reported in the lower Clinch River. If individuals survived, they occurred at very low densities and were undetectable or they had dispersed from the study area through downstream drift or emigration as glochidia attached to host fishes. Low-density populations are difficult to monitor as they are not easily detectable, but more importantly, low numbers can affect success of fertilization, further reducing the probability of natural reproduction and recruitment at self-sustaining levels (Downing et al. 1993). Factors such as predation, host-fish death before glochidial transformation (e.g. natural or artificial infestation induced mortality), excysted juveniles settling into unsuitable substrates, and unfavorable environmental conditions during excystment or settlement (e.g. high flow events) may have contributed to the apparent failure of reintroductions at sites 2 and 3.

Although research in controlled propagation of mussels began over a century ago (Lefevre \& Curtis 1912), there is little information available on survival rates of newly transformed juveniles in the wild or the outcomes from releasing cultured juveniles $(<15 \mathrm{~mm})$ and artificially infested host fishes (Haag 2012). This scarcity of information may be because of short-term difficulty in detection (i.e. individuals are too small), the absence of long-term monitoring programs, or simply because survival-in the form of whether encountering surviving individuals or observing consequent natural recruitment-has not occurred (i.e. negative results were not reported). Overall, we found that restoration projects releasing newly metamorphosed juveniles or artificially infested host fishes have failed to document evidence of post-release survival (Layzer \& Scott 2006; FMCC, Virginia Tech unpublished data; Aquatic Wildlife Conservation Center [AWCC], VDGIF unpublished data). Nevertheless, the Genoa National Fish Hatchery (GNFH), Wisconsin has documented unequivocal success in transformation, settlement, and survival of Lampsilis higginsii (Higgins eye) resulting from releases of over 35,000 infested host fishes over 10 years into the Wisconsin, Iowa, and Wapsipinicon Rivers in Wisconsin and Iowa (N. Eckert 2013, USFWS, GNFH, personal communication).

The failure of released 8-week-old laboratory-propagated juveniles and artificially infested host-fish efforts in this study support the assertion that smaller and younger individuals have a decreased chance of survival when released in the wild relative to larger sub-adults and adults (Sarrazin \& Legendre 2000; Hua et al. 2011). Newly metamorphosed juvenile mussels have a higher incidence of falling prey to a suite of predators, including hydroids, dragonfly larvae, dipteran larvae, crayfishes, and especially flatworms (Zimmerman et al. 2003; Klocker \& Strayer 2004). Further, because small juveniles have more specific microhabitat requirements (e.g. flow at time of release or excystment) for successful settlement into substrate than adult and sub-adults, more factors work against their chances of post-release survival.

To improve success of mussel restorations, it is important to consider biotic and abiotic factors that could limit survival and long-term population viability before reintroducing individuals. Several factors can influence restoration success, including species- and size-specific habitat suitability (including both macro- and microhabitat characteristics), timing of release, host-fish presence and density, handlingand transportation-related stressors, genetic variation among released individuals, condition of released individuals, and environmental stochasticity. Additionally, intensity of the reintroduction effort may be a key to success; as the number of individuals released annually is increased, natural and stress-related mortality may be offset (Griffith et al. 1989; Sarrazin \& Barbault 1996; Sarrazin \& Legendre 2000; Jones et al. 2012; S. Ahlstedt 2013, U.S. Geological Survey [USGS], retired, personal communication).

In this study, the potential effects of these limiting factors on restoration success were controlled by: (1) assessing sites for suitable habitat and water quality prior to releases, (2) conducting releases in late summer and early fall when the reproductive state of mussels was low, (3) implementing optimal transportation and release protocols to reduce stress, (4) confirming the presence of host fishes at reintroduction sites, and (5) fostering genetic diversity. To maintain genetic diversity, translocated adults and those used for host-fish infestations were collected from multiple source populations. Additionally, laboratory culture and artificial infestations of host fish were conducted following controlled propagation policies and guidelines (USFWS \& NOAA 2000; Jones et al. 2006).

Although habitat characteristics of the three sites in our study appeared to be very similar, it could be hypothesized that subtle differences in habitat among the release sites contributed to the apparent failures of reintroduction implemented at sites 2 
and 3. We did not implement reintroduction techniques concurrently at each of the three release sites because of the inability to separate natural recruitment from the multiple releases of 8-week-old laboratory-propagated juveniles or juveniles from artificial infestations (i.e. no identifiable markings or tags). A larger-scale (temporally and spatially) experiment with replication is needed to investigate the effects of habitat characteristics on the success of reintroduction techniques. However, given the similarity of diversity and density of native-mussel species among the three sites (Carey 2013; Table S1 and Table S2, Supporting Information) and their proximity to one another, it is unlikely that differences in habitat alone, if at all, explain the apparent failures at sites 2 and 3 .

Diverse mussel communities provide vital ecosystem services in their ability to filter large portions of the water column and modify habitat (Vaughn et al. 2008). Recovery of populations and maintenance of diversity can be accomplished through well-planned reintroduction and augmentation efforts. Evaluating the effectiveness of species reintroductions provides useful information for managers to make informed decisions when planning mussel population restorations. Our findings demonstrated that successful settlement of released individuals, post-release survival, and natural recruitment - all measures of short-term success - can be accomplished through the release of larger individuals. Based on the variability and generally low success of releases of newly metamorphosed juveniles and artificially infested host fishes that have been implemented over a diversity of habitats in other studies, research supporting the release of larger individuals (Sarrazin \& Legendre 2000; Hua et al. 2011), and the results of this study, it is in all likelihood that the release of larger individuals has a more reliable and accelerated payoff for expediting the recovery of mussel populations.

\section{Acknowledgments}

We thank the many people who helped us complete field work from the USFWS, USGS, VDGIF, The Nature Conservancy (TNC), Tennessee Wildlife Resources Agency, and Virginia Tech. Thanks to the USFWS Gloucester, Virginia, and Asheville, North Carolina, Field Offices for their financial support and to Dr. Marcella Kelly for her technical assistance. We especially thank Dr. Braven Beaty of TNC, Abingdon, Virginia, and Michael Pinder of VDGIF for their involvement in the project and for access to Cleveland Islands. We also thank staff at VDGIF's AWCC, Marion, Virginia, for producing and releasing the LPSAs in the Clinch River at Cleveland Islands. The views expressed in this article are those of the authors and do not necessarily represent those of the USFWS.

\section{LITERATURE CITED}

Ahlstedt S (1979) Recent mollusk transplants into the North Fork Holston River in southwestern Virginia. Bulletin of the American Malacological Union 1979:21-23

Barnhart MC (2006) Buckets of muckets: a compact system for rearing juvenile freshwater mussels. Aquaculture 254:227-233
Carey CS (2013) An evaluation of population restoration and monitoring techniques for freshwater mussels in the upper Clinch River, Virginia, and refinement of culture methods for laboratory-propagated juveniles. Master's thesis. Virginia Polytechnic Institute and State University, Blacksburg

Center for Mollusk Conservation (2009) Advances in the propagation of rare and endangered mussel species. Annual Research Highlights 2008 for the Kentucky Department of Fish and Wildlife Resources 2:46-48

Cope GW, Waller DL (1995) Evaluation of freshwater mussel relocation as a conservation and management strategy. Regulated Rivers: Research \& Management 11:147-155

Downing JA, Rochon Y, Pérusse M, Harvey H (1993) Spatial aggregation, body size, and reproductive success in the freshwater mussel Elliptio complanata. Journal of the North American Benthological Society 12:148-156

Eckert NL, Pinder MJ (2010) Freshwater mussel survey of Cleveland Island, Clinch River, Virginia: augmentation monitoring site 2008. Virginia Department of Game and Inland Fisheries, Richmond, Virginia

Griffith B, Scott JM, Carpenter JW, Reed C (1989) Translocation as a species conservation tool: status and strategy. Science 245:477-480

Haag WR (2012) North American freshwater mussels: natural history, ecology, and conservation. Cambridge University Press, New York

Haag WR, Williams JD (2014) Biodiversity on the brink: an assessment of conservation strategies for North American freshwater mussels. Hydrobiologia 735:45-60

Hua D, Rogers J, Jones J, Neves R (2011) Propagation, culture, and monitoring of endangered mussels for population restoration in the Clinch and Powell Rivers, Tennessee, 2006-2010, Report to the Tennessee Wildlife Resources Agency, Nashville, Tennessee

Jones JW, Neves RJ (2011) Influence of life-history variation on demographic responses of three freshwater mussel species (Bivalvia: Unionidae) in the Clinch River, U.S.A. Aquatic Conservation: Marine and Freshwater Ecosystems 21:57-73

Jones JW, Mair RA, Neves RJ (2005) Factors affecting survival and growth of juvenile freshwater mussels cultured in recirculating aquaculture systems. North American Journal of Aquaculture 67:210-220

Jones JW, Hallerman EM, Neves RJ (2006) Genetic management guidelines for captive propagation of freshwater mussels (Unionidae). Journal of Shellfish Research 25:527-535

Jones JW, Neves RJ, Hallerman EM (2012) Population performance criteria to evaluate reintroduction and recovery of two endangered mussel species, Epioblasma brevidens and Epioblasma capsaeformis (Bivalvia: Unionidae). Walkerana, Journal of the Freshwater Mollusk Conservation Society $15: 27-44$

Jones J, Ahlstedt S, Ostby B, Beaty B, Pinder M, Eckert N, et al. (2014) Clinch River freshwater mussels upstream of Norris Reservoir, Tennessee and Virginia: a quantitative assessment from 2004 to 2009. Journal of the American Water Resources Association 50:820-836

Klocker CA, Strayer DL (2004) Interactions among an invasive crayfish (Orconectes rusticus), a native crayfish (Orconectes limosus), and native bivalves (Sphaeriidae and Unionidae). Northeastern Naturalist 11:167-178

Layzer JB, Scott EM Jr (2006) Restoration and colonization of freshwater mussels and fish in a southeastern United States tailwater. River Research and Applications 22:475-491

Lefevre G, Curtis WC (1912) Studies on the reproduction and artificial propagation of freshwater mussels. Bulletin of the Bureau of Fisheries 30:105-201

Neves RJ, Bogan AE, Williams JD, Ahlstedt SA, Hartfield PW (1997) Status of aquatic mollusks in the southeastern United States: a downward spiral of diversity. Pages 43-85. In: Benz GW, Collins DE (eds) Aquatic fauna in Peril: the southeastern perspective Special publication 1, Southeast Aquatic Research Institute. Lenz Design and Communications, Decatur, Georgia

Price JE, Zipper CE, Jones JW, Franck CT (2014) Water and sediment quality in the Clinch River, Virginia and Tennessee, U.S.A., over nearly five decades. Journal of the American Water Resources Association 50:837-858

Sarrazin F, Barbault R (1996) Reintroduction: challenges and lessons for basic ecology. Trends in Ecology \& Evolution 11:474-478 
Sarrazin F, Legendre S (2000) Demographic approach to releasing adults versus young in reintroductions. Conservation Biology 14:488-500

Sheehan RJ, Neves RJ, Kitchel HE (1989) Fate of freshwater mussels transplanted to formerly polluted reaches of the Clinch and North Fork Holston Rivers, Virginia. Journal of Freshwater Ecology 5:139-149

Smith DR, Villella RF, Lemarié DP (2001) Survey protocol for assessment of endangered freshwater mussels in the Allegheny River, Pennsylvania. Journal of the North American Benthological Society 20:118-132

Teixeira CP, Schetini de Azevedo C, Mendl M, Cipreste C, Young RJ (2007) Revisiting translocation and reintroduction programmes: the importance of considering stress. Animal Behaviour 73:1-13

USFWS (U.S. Fish and Wildlife Service) (2004) Recovery plan for Cumberland elktoe (Alasmidonta atropurpurea), oyster mussel (Epioblasma capsaeformis), Cumberlandian combshell (Epioblasma brevidens), purple bean (Villosa perpurpurea), and rough rabbitsfoot (Quadrula cylindrica strigillata), U.S. Fish and Wildlife Service, Southeast Region, Atlanta, Georgia

USFWS and NOAA (U.S. Fish and Wildlife Service and National Oceanic and Atmospheric Administration) (2000) Policy regarding controlled propagation of species listed under the Endangered Species Act. Federal Register $65: 56916-56922$

Coordinating Editor: Gary Kendrick
Vaughn CC, Nichols SJ, Spooner DE (2008) Community and foodweb ecology of freshwater mussels. Journal of the North American Benthological Society 27:409-423

Zimmerman LL, Neves RJ, Smith DG (2003) Control of predaceous flatworms Macrostomum sp. in culturing juvenile freshwater mussels. North American Journal of Aquaculture 65:28-32

\section{Supporting Information}

The following information may be found in the online version of this article:

Table S1. Mean densities $( \pm$ SE) of species collected from the upper Clinch River, Virginia, at each reintroduction site using systematic quadrat sampling in 2011 and 2012. Species densities of zero signify that densities may be too low to be detected or these species are not present at a site.

Table S2. Ranges of sizes ( $\mathrm{mm}$ ) for species collected in the upper Clinch River, Virginia, at each reintroduction site using systematic quadrat sampling in 2011 and 2012 .

Received: 30 May, 2014; First decision: 25 August, 2014; Revised: 26 January, 2015; Accepted: 27 January, 2015 